\title{
Success or Failure in Knowledge Management Systems: A Universal Issue ${ }^{*, * *}$
}

\author{
Elayne Coakes ${ }^{1}$, A.D. Amar ${ }^{2}$, and Maria L. Granados ${ }^{1}$ \\ ${ }^{1}$ Westminster Business School, University of Westminster, 35 Marylebone Road \\ London, NW1 5LS, UK \\ \{coakese, m.granados\} @westminster.ac.uk \\ ${ }^{2}$ Stillman School of Business, Seton Hall University, South Orange, NJ 07079, USA \\ Ad.amar@shu . edu
}

\begin{abstract}
This paper takes a sociotechnical viewpoint of knowledge management system (KMS) implementation in organizations considering issues such as stakeholder disenfranchisement, lack of communication, and the low involvement of key personnel in system design asking whether KMS designers could learn from applying sociotechnical principles to their systems. The paper discusses design elements drawn from the sociotechnical principles essential for the success of IS and makes recommendations to increase the success of KMS in organizations. It also provides guidelines derived from Clegg's Principles (2000) for KMS designers to enhance their designs. Our data comes from the application of a plurality of analysis methods on a large comprehensive global survey conducted from 2007 to 2011 of 1034 participants from 76 countries. The survey covers a variety of organizations of all types and sizes from a comprehensive selection of economic sectors and industries. Our results showed that users were not satisfied with the information and knowledge systems that they were being offered. In addition to multiple technology and usability issues, there were human and organisational barriers that prevented the systems from being used to their full potential. We recommend that users of KMS are integrated into the design team so that these usability and other barriers can be addressed during the feasibility stage as well as the actual design and implementation phases.
\end{abstract}

\section{Introduction}

Despite much theoretical (e.g., DeLone and McLean (1992; 2003)) and some practical works within organisations that study measures of organizational support such as

\footnotetext{
* To maintain the page limit imposed by IFIP 8.6, we eliminated a number of tables, literature, and other information from this paper. Interested readers may contact authors for them.

** With acknowledgements to the researchers who prepared much of the TAM literature review for the TWOLER project at the University of Westminster. The authors wish to thank JISC and the Promoting Student Web 2.0 Contributions with Lightweight Enterprise RSS project who provided grant support for the sociotechnical evaluation study. Thanks to Institute for International Business at Seton Hall University for the travel related grants pertaining to this project.
} 
leadership, incentives, co-worker and supervisor (e.g., Kulkarni, Ravindran, and Freeze (2006)), we still find that many systems fail on their first implementation, or even fail altogether. These failures appear to refer to all types of information systems (IS) in all fields of organisational life. Not enough attention has been paid to understand the failures especially through a broad-based study of all stakeholders in design, implementation and use of knowledge management systems (KMS). The few studies undertaken about knowledge management systems failures seem to indicate that knowledge management systems fail at least as often, if not more often, than any other information system. User experience builds their beliefs about system quality and knowledge/information quality which determines KMS use (Wu and Wang, 2006).

While DeLone and McLean (2002) did modify their original IS success model by converting Individual Impact and Organizational Impact to Net Impact (DeLone and McLean, 1992), KMS specific quantitative impacts could not be measured either at individual or organizational level (Jennex and Olfman, 2003). Davenport, DeLone, and Beers (1998), in the context of KM projects, consider senior management support, motivational incentives, and knowledge friendly culture among their eight factors for success. In their KM success model, Massey, Montoya-Weiss, and O'Driscoll (2002) consider three key managerial influences: coordination, control, and measurement; disciplined project management; and leadership. However, no study considered detailed sociotechnical factors in a wide population of KMS users, managers, and knowledge workers. The question, therefore, this paper addresses is: what can KMS designers learn from sociotechnical principles to improve the success rate, and avoid the failure rates of these systems, and reduce user experiences and beliefs about system quality and knowledge/information quality that then discourage KMS use? In particular, the paper addresses the underlying factors that cause failure in three specific sociotechnical areas: technology; human; and organisational. Additionally, it investigates the underlying organisational, human and technical conditions that should be put in place as part of the overall knowledge management system design.

The reasons for KMS failure are multi-faceted and both social and technical factors are involved as well as organisational factors. For instance; authors such as Hurley (2010) argue that hierarchical organisations are not conducive to knowledge sharing and that additionally, unless it is a cultural norm that knowledge is shared, systems will not work. Technology, they state, cannot be the driver, but can facilitate when the culture is appropriate. Akhavan, Jafari, and Fathian (2005) agree. In their list of the 10 most important failure factors not only do they mention organisational culture but additionally they echo a number of points which we saw identified in our survey (details given below) such as the lack of budget; lack of top management support; resistance to change; and current and new systems being unable to link. Many of these factors are also to be found in all information systems failures and thus we would argue that considering the sociotechnical factors of knowledge management systems is equally appropriate for considering how KMS might achieve success as for any other information system (IS).

This paper therefore takes a sociotechnical viewpoint of knowledge management system implementation in organisations and evaluates their success and failure across a variety of organisations and industrial sectors with data taken from a worldwide study. 
The data which is presented is derived from what we assert is the largest global knowledge management survey of knowledge workers ever undertaken with 1034 participants across 76 countries coming from a balanced sample of organisations in terms of sector, size and status. Additionally, 15 in-depth interviews with company directors and CEOs were conducted. This data was analysed through both qualitatively and quantitatively as appropriate and the statistical results were valid to the $95 \%$ of significance. Content analysis was used on the qualitative data and multi-rating was utilised to ensure its validity.

Our results showed that users were not satisfied with the information and knowledge systems that they were being offered. In addition to multiple technology and usability issues, there were additionally human and organisational barriers that prevented the systems from being used to their full potential. A sociotechnical evaluation would indicate that this was not unexpected considering the ways in which these systems had been implemented. A high failure rate is to be expected when stakeholders are not consulted in how they undertake their work and which technologies are best fit for the purpose.

The paper begins with a discussion of sociotechnical evaluation methods for organisational projects emphasising the design elements considered essential for project success. This is followed by a brief discussion of the sixteen major models used for system evaluations and their linkage into the sociotechnical principles which permitted us to derive our propositions for likely knowledge management system success. We then discuss our empirical data and the research methodology utilised.

Finally we link our data to the propositions and discuss the validity of theory against practice. We suggest the major implications of this study for future knowledge management system design and implementation, providing advice for knowledge management managers and system designers of better ways to design such systems.

\section{Sociotechnical Considerations}

Coakes and Coakes (2005) said that sociotechnical thinking is important to the design, development, implementation, and use of information technology systems in organisations. It addresses vital issues in combining the use of powerful information and communication technologies with effective and humanistic use of people. Sociotechnical perspectives can be characterised as being holistic and will take a more encompassing view of the organisation, its stakeholders in knowledge, and the environment in which it operates.

Coiera (2007) argues that sociotechnical design and evaluation are inter-related processes where one affects the other. Evaluation can be of two types: summative whereby there is a test of hypotheses as to whether the system met the user needs; or formative - where there is an analysis of needs. Some sociotechnical designs can be provocative when finding out about user needs. Coiera (2007) is critical of the Technology Acceptance Model (TAM) concepts as they focus on individuals and the fit between task, technology, and individuals but ignore the organisational or task context. Many articles in the 1990s used the TAM model, or its extensions, as a substitute for sociotechnical models (Whitworth et al, 2008), thus concentrating closely on the software interaction with the organisational users. This limited view of the 
sociotechnical mindset is followed by Dixon (1999) using the ITAM framework (Information Technology Acceptance Model); Tsinakis, Kouroubali (2009) using the FITT (fit between individuals, task and technology) framework; and Peute et al (2010), who use the UIS (User Interaction Satisfaction) concept. Berg (1999) also follows the 'herd' through discussing sociotechnical evaluation solely in the context of an information technology system and the existing work practices that it will impact.

A contrasting view to more modest evaluation concepts in regard to success and failure is that of Clegg (2000) who considers the entirety of the organisation and not just the system under consideration. This viewpoint is more aligned with the original sociotechnical principles as laid out by Cherns (1976) for organisational design. Reading his paper of 2000 (Clegg, 2000) and also Cherns (1976; 1987), we can derive some evaluation questions that need to be asked of any system whether or not it is a knowledge management system or a more standard information system. These principles and evaluation questions will equally apply.

Having derived post-hoc evaluation questions we can then say that these questions can also be used as questions to be asked during the design and implementation process by changing the tense of the question to the present and/or future. Thus 'was' would become 'is' and so on. These questions then become ones that should underpin all new knowledge management system design projects.

\subsection{Clegg's 19 Sociotechnical Design Principles}

Clegg's (2000) 19 principles are divided into 3 sections: Meta Principles; Content Principles; and Process Principles; and each Principle 'acquires' a set of questions that needs to be answered when designing according to these sociotechnical principles. Clegg's work is drawn from the seminal set of principles outlined by Cherns (1976; 1987).

In Table 1, we look at these principles and identify the questions that they must raise in terms of not just past evaluation of the success or failure of any information systems including that of KMS, but also how to design new systems that can succeed.

Table 1. Clegg's Principles and the Related Evaluation Questions

\begin{tabular}{|c|c|c|}
\hline & Clegg's Principle & $\begin{array}{l}\text { Design and Implementation Questions: } \\
\text { Use also for post-hoc Evaluation }\end{array}$ \\
\hline \multicolumn{3}{|c|}{ Meta principles } \\
\hline 1 & Systemic Design & $\begin{array}{l}\text { Is there a built in capacity to / or a built } \\
\text { in process to review the impacts of } \\
\text { current design and make amends accor- } \\
\text { dingly? } \\
\text { Reflexivity leading to action and } \\
\text { re-action. }\end{array}$ \\
\hline 2 & Centrality of Values and Mindset & $\begin{array}{l}\text { Do the technical design / technologies } \\
\text { support the human [resources] to meet } \\
\text { their goals? Do their goals meet / com- } \\
\text { plement the needs of the systems/s? }\end{array}$ \\
\hline
\end{tabular}


Table 1. (continued)

\begin{tabular}{|c|c|c|}
\hline 3 & \multirow{2}{*}{$\begin{array}{l}\text { Design involves making choices } \\
\text { Design should be business reflected } \\
\text { Design should be user reflected } \\
\text { Design should be manager reflected }\end{array}$} & $\begin{array}{l}\text { Can stakeholders influence the design? } \\
\text { Whose needs could be met? }\end{array}$ \\
\hline 4 & & $\begin{array}{l}\text { Does the technical design reflect the } \\
\text { result of a fad? }\end{array}$ \\
\hline 5 & Design is a social process & $\begin{array}{l}\text { Do the structures permit of evolution } \\
\text { after stakeholder views are aired? Can } \\
\text { stakeholders influence the design? }\end{array}$ \\
\hline 6 & Design is socially shaped & $\begin{array}{l}\text { Is the design / technology the result of } \\
\text { movements in the external world? What } \\
\text { social movements impact this design? }\end{array}$ \\
\hline 7 & Design is contingent & $\begin{array}{l}\text { Are the choices contingent on decisions } \\
\text { and the satisficing }{ }^{1} \text { of goals? }\end{array}$ \\
\hline \multicolumn{3}{|c|}{ Content principles } \\
\hline 8 & Core processes should be integrated & Are the systems integrated? \\
\hline 9 & $\begin{array}{l}\text { Design entails multiple task alloca- } \\
\text { tions between and amongst humans } \\
\text { and machines }\end{array}$ & $\begin{array}{l}\text { Are the possible tasks explicitly allo- } \\
\text { cated to either technology or humans? }\end{array}$ \\
\hline 10 & $\begin{array}{l}\text { System components should be } \\
\text { congruent }\end{array}$ & $\begin{array}{l}\text { Are the systems consistent? Can those } \\
\text { who need to take the necessary action? } \\
\text { Can they obtain the information they } \\
\text { need? }\end{array}$ \\
\hline 11 & $\begin{array}{l}\text { Systems should be simple in design } \\
\text { and make problems visible }\end{array}$ & $\begin{array}{l}\text { Is it easy to identify problem areas and } \\
\text { allocate resources? }\end{array}$ \\
\hline 12 & $\begin{array}{l}\begin{array}{l}\text { Problems should be controlled at } \\
\text { source }\end{array} \\
\end{array}$ & Can problem areas be easily identified? \\
\hline 13 & $\begin{array}{l}\text { The means of undertaking tasks } \\
\text { should be flexibly specified }\end{array}$ & $\begin{array}{l}\text { Can users have choices in using the } \\
\text { systems? Are there alternatives in how } \\
\text { tasks are performed? }\end{array}$ \\
\hline \multicolumn{3}{|c|}{ Process principles } \\
\hline 14 & $\begin{array}{l}\text { Design practice is itself a socio- } \\
\text { technical system }\end{array}$ & $\begin{array}{l}\text { Does the process of design follow the } \\
\text { meta principles? }\end{array}$ \\
\hline 15 & $\begin{array}{l}\text { Systems and their designers should } \\
\text { be owned by their managers and } \\
\text { users }\end{array}$ & $\begin{array}{l}\text { Who owns the system design? And the } \\
\text { systems that are designed? }\end{array}$ \\
\hline 16 & $\begin{array}{l}\text { Evaluation is an essential aspect of } \\
\text { design }\end{array}$ & $\begin{array}{l}\text { Is there reflective action? Who influ- } \\
\text { ences the design? What are the goals } \\
\text { against which this reflection could be } \\
\text { measured? }\end{array}$ \\
\hline
\end{tabular}

\footnotetext{
${ }^{1}$ Satisficing is a term used to describe how people make rational choices between options open to them and within prevailing constraints. Herbert Simon (Administrative Behaviour, 1957) argued that decision-makers can rarely obtain and evaluate all the information which could be relevant to the making of a decision. Instead, they work with limited and simplified knowledge, to reach acceptable, compromise choices.
} 
Table 1. (continued)

\begin{tabular}{|c|l|l|}
\hline $\mathbf{1 7}$ & $\begin{array}{l}\text { Design involves multidisciplinary } \\
\text { education. }\end{array}$ & $\begin{array}{l}\text { What disciplines do the designers come } \\
\text { from? }\end{array}$ \\
\hline $\mathbf{1 8}$ & $\begin{array}{l}\text { Sufficient resources and support } \\
\text { are required for design }\end{array}$ & Is this true? \\
\hline $\mathbf{1 9}$ & $\begin{array}{l}\text { System design involves political } \\
\text { processes }\end{array}$ & $\begin{array}{l}\text { Is there a diversity of views? Who in- } \\
\text { fluences the change process? Do orga- } \\
\text { nisational politics play a part in the } \\
\text { design process? }\end{array}$ \\
\hline
\end{tabular}

The comprehensive literature review we undertook permitted us to formulate the following propositions about stakeholder behaviour towards systems. These propositions were derived from the operationalism of the models as applied to users of the systems, i.e., what the users thought and how they intended to behave, or did behave, towards the system as identified in these models. Additionally the variables and meaning identified were used to refine these propositions.

\subsection{Propositions}

P1. $\quad$ System performance has an influence on intention to use the system;

$P 2$. Effort required to be expended has an influence on intention to use the system;

P3. Attitude toward using technology (now or prior to using) has an influence on intention to use the system;

P4. Attitude toward using technology will not have significant influence on intention to use the system;

P5. Social Influence has an influence on intention to use the system;

P6. Facilitating conditions have an influence on behavioural intention to use the system;

P7. Self-efficacy (ability to influence, affect, or time required to affect) has an influence on intention to use the system;

P8. Computer self-efficacy will not have a significant influence on intention; P9. Anxiety has an influence on intention to use the system;

P10. Computer anxiety will not have a significant influence on intention to use the system;

P11. Facilitating conditions have an influence on usage of the system;

P12. Facilitating conditions will not have a significant influence on intention to use the system;

P13. Behavioural intention will have a significant positive influence on usage of the system;

P14. The influence of performance on intentions will be moderated by social influence; P15. Social Influence on intentions will be moderated in mandatory settings (i.e. where usage is compulsory).

The above inferences related to the causal factors of KMS usage were used as propositions when designing and analysing our research data. 
In the following section, we describe our research methods and how our primary data was collected. We then demonstrate our analysis methods, and in our Findings, we discuss what we have discovered and the veracity or not of our propositions. Finally, we discuss the implications from our research both theoretical and empirical, for organisations in implementing more successful knowledge management systems.

\section{Research Methods}

\subsection{Content Analysis}

We utilised content analysis to discover the theming of the open-ended responses to our questions. Content analysis is used in qualitative and inductive research for thematic purposes: for the analysis of words and phrases. It provides an objective, systematic description of the content of text and determines the presence of certain textual items such as words, phrases, etc. that are repeated and thus can be quantified or 'themed'.

The text is assigned a code - and broken down into 'chunks'. Each piece of text is coded to assign it a value type - and to identify whether it is related to other pieces of text. Thus, typically the researcher is looking for key phrases that are repeated across texts. It also permits relational analysis so as to make the connections from the concept and identify which concepts are related to which others (Stemler, 2001).

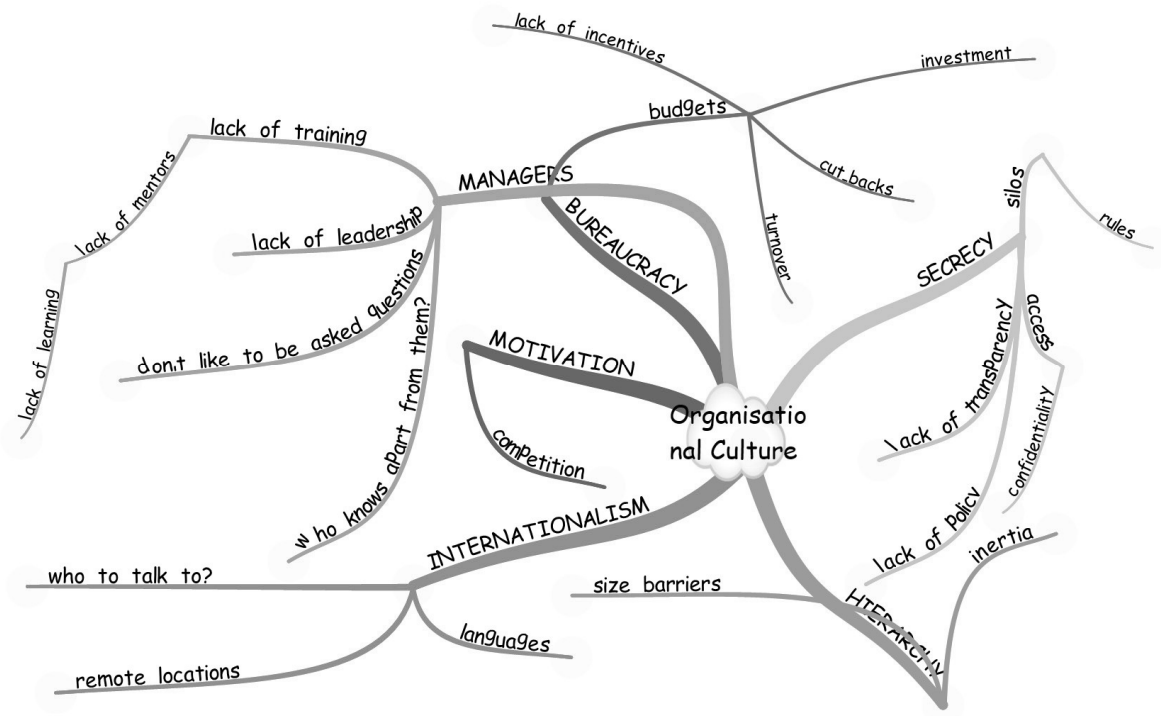

Fig. 1. Mindmap of Organizational Barriers

Content analysis is a reliable technique that enables researchers to sift and categorise large volumes of data in a systematic fashion. It permits inferences that can be later triangulated with other methods of data collection. In particular it examines patterns and trends in documents and establishes themes and concepts that are repeated. 
The results are then an objective assessment of inferences about the data messages and can identify intentions, biases, prejudices and oversights amongst other themes (Berelson, 1952).

We have mapped the content into mindmaps (see Figure1 as an example of these maps) for a pictorial representation of the main issues identified by our participants.

\subsection{Sampling}

Our sample for this survey was a convenience sample of knowledge workers, whereby people were invited by email, mailing lists and websites to complete the survey, and additionally, word of mouth was used to complete the survey. Whilst the complete survey received 1034 participants, the open-ended responses were from just over 100 participants. However, this is still a very high number of responses for analysis and to suggest a qualitative validity of the outcomes.

We argue that in undertaking the analysis of our research we should take a realist, positivist, and nomothetic approach. Thus contradictions can be seen but by using multi-methods and approaches, triangulation occurs, and the research approaches both the social element through subjectivism and the technical element through a deterministic method, such as a survey.

Triangulation is used to counter the criticisms that are usually levelled at social researchers - the subjectivism of their approach. It is also used to provide the means by which the interpretivist principle of suspicion is addressed (Klein and Myers, 1999) which requires sensitivity to possible biases in the minds and assumptions of both the researchers and the participants and to alleviate any distortions in the narratives collected through, for instance, interviews.

When designing this research it was vital to be aware of the following five things: (a) the questions; (b) the propositions; (c) the unit of analysis; (d) the logic that links the data to the propositions; and (e) the criteria for interpreting the findings. Each proposition must direct attention to something to be examined within the scope of study. Each piece of data collected should also match to the propositions taking into consideration that a real-world situation, which is what is being considered in this study, is inevitably complex and multi-dimensional and, thus, any proposition, it can be argued, can be matched to more than one type of data.

It is important to note that we piloted the survey pre-general circulation to test understanding of the questions and to ensure that the answers that we were receiving were as expected. A small number of adjustments were made as a result of this pilot.

\section{$4 \quad$ Findings}

The content analysis of the free-form text inputted into the survey demonstrated that there were significant issues in all three of the identified areas: human, organisational and technological. Clearly, as some of our participants were not from either the UK or the US you might expect that, for some countries, the technology might not be sophisticated or that there might be other technical issues related to the country's 
infrastructure, however there were far more comments about technological issues than one might therefore have expected (See Table 2). We rationalize that people tolerate, accept, and adapt to the flaws in technology and work with these flaws and still gain success by gaining control over it. However, when it comes to people and organization, the respondents believe that these are as much a barrier as technology. They feel helpless about their expected behaviour and experience barriers that will not permit them to bring success to KMS in their organization.

Table 3 presents the type of responses obtained for the three areas, including the number and percentage of participants that did not identify those barriers in their organisations. Of the 108 participants that answered the open questions, $18 \%$ did not encounter technology barriers in locating this knowledge in their organisations; $17.6 \%$ did not encounter organisational barriers; but only $5.6 \%$ did not encounter human barriers.

Table 2. Number and Percentage of Responses to Technology, Human and Organisational Barriers per Country

\begin{tabular}{|l|c|c|c|c|c|c|}
\hline & \multicolumn{2}{|c|}{ Human barriers } & \multicolumn{2}{c|}{$\begin{array}{c}\text { Technology } \\
\text { barriers }\end{array}$} & \multicolumn{2}{c|}{$\begin{array}{c}\text { Organisational } \\
\text { barriers }\end{array}$} \\
\hline & Freq. & $\%$ & Freq. & $\%$ & Freq. & $\%$ \\
\hline United States & 49 & $60.5 \%$ & 43 & $59.7 \%$ & 39 & $55.7 \%$ \\
\hline United Kingdom & 10 & $12.3 \%$ & 9 & $12.5 \%$ & 10 & $14.3 \%$ \\
\hline Australia & 6 & $7.4 \%$ & 6 & $8.3 \%$ & 6 & $8.6 \%$ \\
\hline India & 5 & $6.2 \%$ & 5 & $6.9 \%$ & 4 & $5.7 \%$ \\
\hline Canada & 3 & $3.7 \%$ & 2 & $2.8 \%$ & 3 & $4.3 \%$ \\
\hline Brazil & 1 & $1.2 \%$ & 1 & $1.4 \%$ & 1 & $1.4 \%$ \\
\hline Bulgaria & 1 & $1.2 \%$ & 0 & $0.0 \%$ & 0 & $0.0 \%$ \\
\hline France & 1 & $1.2 \%$ & 1 & $1.4 \%$ & 1 & $1.4 \%$ \\
\hline Latvia & 1 & $1.2 \%$ & 1 & $1.4 \%$ & 1 & $1.4 \%$ \\
\hline Netherlands & 1 & $1.2 \%$ & 2 & $2.8 \%$ & 2 & $2.9 \%$ \\
\hline Pakistan & 1 & $1.2 \%$ & 1 & $1.4 \%$ & 1 & $1.4 \%$ \\
\hline Philippines & 1 & $1.2 \%$ & 1 & $1.4 \%$ & 1 & $1.4 \%$ \\
\hline Sweden & 1 & $1.2 \%$ & 0 & $0.0 \%$ & 1 & $1.4 \%$ \\
\hline Grand Total & $\mathbf{8 1}$ & & $\mathbf{7 2}$ & & $\mathbf{7 0}$ & \\
\hline
\end{tabular}


Table 3. Responses to Organisational, Technical and Human Barriers

\begin{tabular}{|l|c|c|c|c|c|c|}
\hline & \multicolumn{2}{|c|}{$\begin{array}{c}\text { Technology } \\
\text { barriers }\end{array}$} & \multicolumn{2}{c|}{$\begin{array}{c}\text { Human bar- } \\
\text { riers }\end{array}$} & \multicolumn{2}{c|}{$\begin{array}{c}\text { Organisational } \\
\text { barriers }\end{array}$} \\
\hline Open responses & 82 & $75.9 \%$ & 97 & $89.8 \%$ & 77 & $71.3 \%$ \\
\hline No barriers & 20 & $18.5 \%$ & 6 & $5.6 \%$ & 19 & $17.6 \%$ \\
\hline No valid responses & 6 & $5.6 \%$ & 5 & $4.6 \%$ & 12 & $11.1 \%$ \\
\hline Grand Total & $\mathbf{1 0 8}$ & & $\mathbf{1 0 8}$ & & $\mathbf{1 0 8}$ & \\
\hline
\end{tabular}

So we can clearly see from this result that human barriers remain the major issue with knowledge sharing wherever people are located. Comments such as:

People are busy with what they think is their "own work."

Sometimes, it is difficult to find the time to help others.

Or silos and turf

were common complaints from all participants - we saw this issue also in the main survey - see Figure 2.

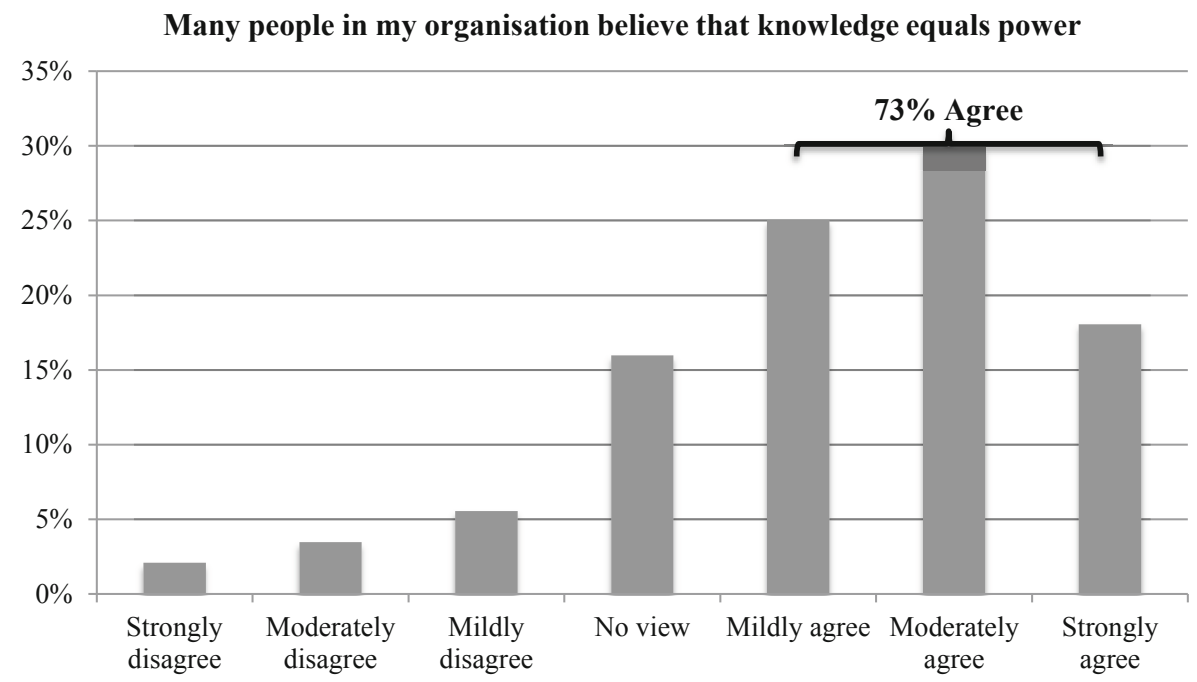

Fig. 2. Knowledge Equals Power

We saw during our interviews that the additional issues were raised as reasons why their knowledge management initiative was failing - see Figure 3. Silos were the central issue but we also saw that the constantly changing organisational environment made it difficult to identify and ensure that relevant knowledge was shared; and that there were many delays in implementing such knowledge sharing programmes from management levels, who may not think it a high enough priority to counter delays from service or technology providers. 


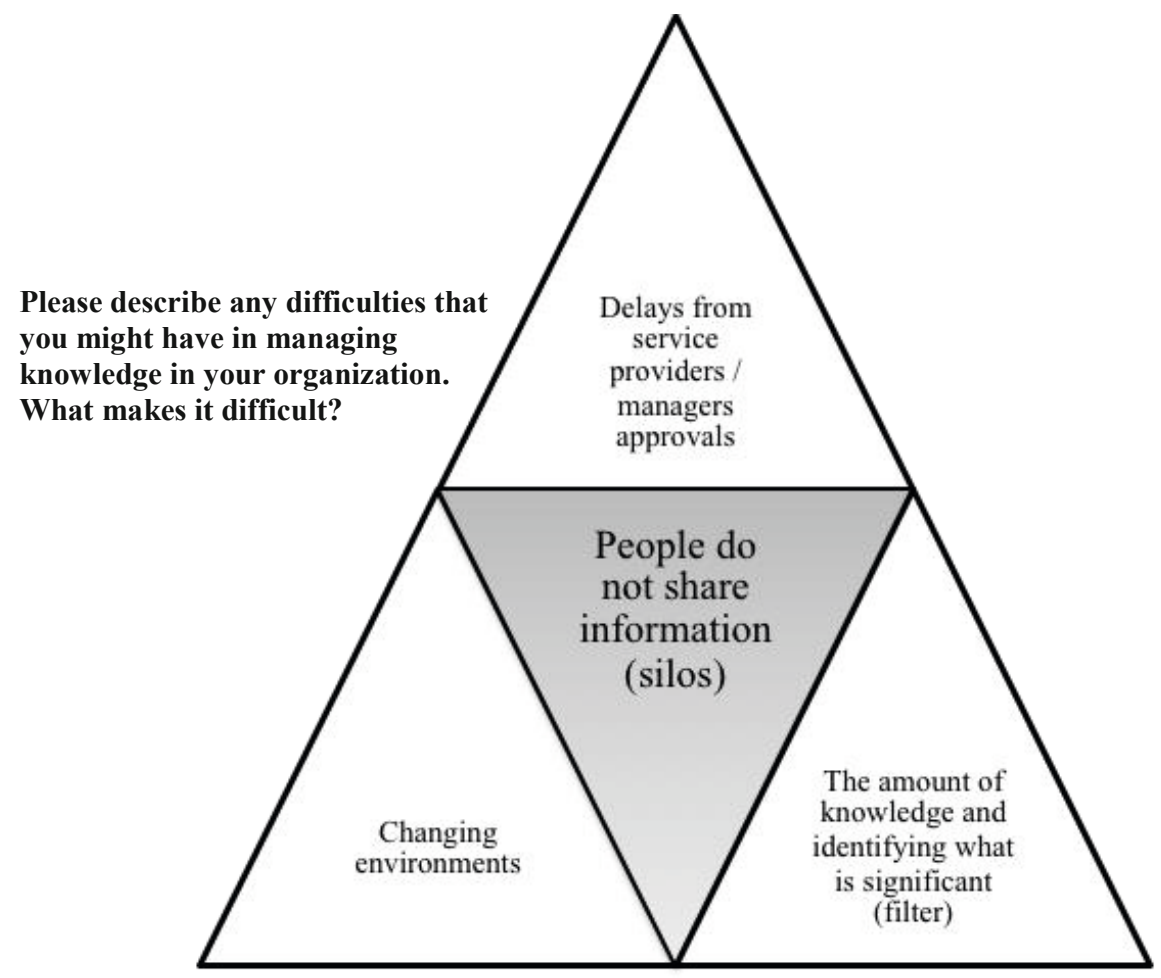

Fig. 3. Difficulties in Managing Knowledge

\section{How to enhance KM}

What more, if anything, would you like to do to enhance knowledge management in your organization?

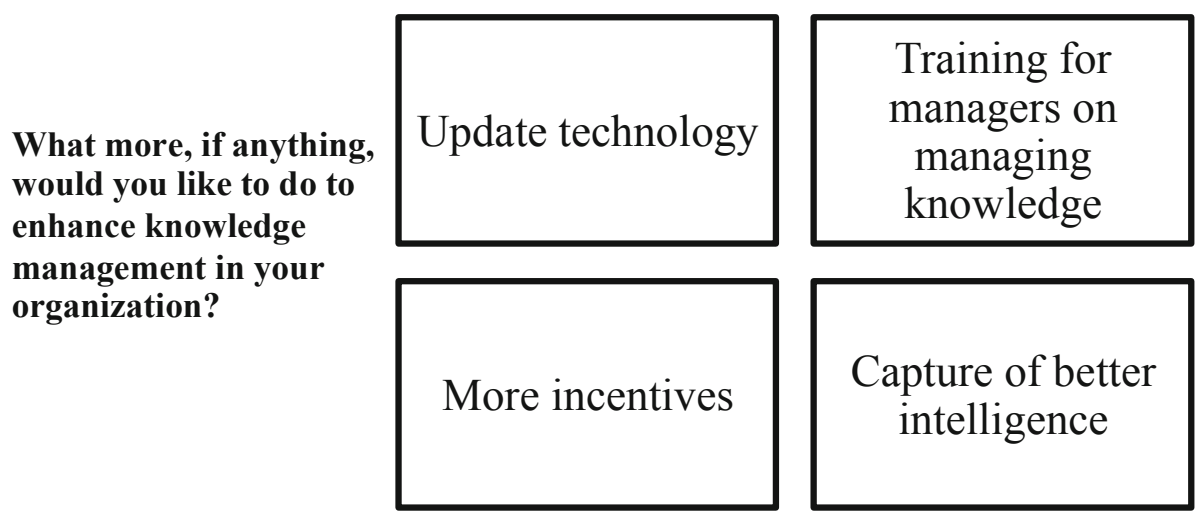

Fig. 4. Enhancing Knowledge Management 
Many suggested that this was as a response to a lack of clarity about knowledge management training and strategy from managers and the central organisation. Figure 4 demonstrates some of the ideas that our participants had about how to improve their knowledge management performance.

\subsection{Propositions and Findings}

Table 4 illustrates verbatim participant comments alongside our propositions. Each quote comes from a different participant and is indicated by the quotation marks. Major grammatical errors are theirs; we have not attempted to adjust their use of English too much.

Table 4. Propositions vs. Findings of Content Analysis of Free-Form Text

\begin{tabular}{|c|c|c|c|c|}
\hline \multirow[b]{2}{*}{$\begin{array}{c}\text { Pro } \\
\text { p. } \\
\text { No. }\end{array}$} & \multirow[b]{2}{*}{ Proposition } & \multicolumn{3}{|c|}{\begin{tabular}{|l|} 
Quotes from Survey Participants Supporting \\
Propositions
\end{tabular}} \\
\hline & & Technology & Human & $\begin{array}{c}\text { Organisa- } \\
\text { tional }\end{array}$ \\
\hline 1. & $\begin{array}{l}\text { System perfor- } \\
\text { mance has an } \\
\text { influence on in- } \\
\text { tention to use the } \\
\text { system }\end{array}$ & $\begin{array}{l}\text { - "If our company } \\
\text { server is down or } \\
\text { not working prop- } \\
\text { erly we cannot get } \\
\text { into any informa- } \\
\text { tion that is saved } \\
\text { on it." } \\
\text { "Major barriers } \\
\text { would be slow } \\
\text { internet connec- } \\
\text { tion or no internet } \\
\text { connection." }\end{array}$ & & \\
\hline 2. & $\begin{array}{l}\text { Effort required } \\
\text { to be expended } \\
\text { has an influence } \\
\text { on intention to } \\
\text { use the system }\end{array}$ & $\begin{array}{l}\text { - "I do not know } \\
\text { where to look for } \\
\text { knowledge on the } \\
\text { computer system } \\
\text { in my company." } \\
\text { - "complicated } \\
\text { software" }\end{array}$ & & \\
\hline 3. & $\begin{array}{l}\text { Attitude toward } \\
\text { using technology } \\
\text { (now or prior to } \\
\text { using) has an } \\
\text { influence on in- } \\
\text { tention to use the } \\
\text { system }\end{array}$ & $\begin{array}{l}\text { - "Technology } \\
\text { itself doesn't give } \\
\text { any guidance on } \\
\text { the contents of or } \\
\text { access to what's in } \\
\text { people's heads. It } \\
\text { can facilitate } \\
\text { tracking down } \\
\text { information or }\end{array}$ & & \\
\hline
\end{tabular}




\begin{tabular}{|c|c|c|c|c|}
\hline & & $\begin{array}{l}\text { knowledge howev- } \\
\text { er, by making } \\
\text { information ac- } \\
\text { cessible electroni- } \\
\text { cally". }\end{array}$ & & \\
\hline 4. & $\begin{array}{l}\text { Attitude toward } \\
\text { using technology } \\
\text { will not have } \\
\text { significant influ- } \\
\text { ence on intention. }\end{array}$ & $\begin{array}{l}\text { - "None } \\
\text { really" }\end{array}$ & & \\
\hline 5. & $\begin{array}{l}\text { Social Influence } \\
\text { has an influence } \\
\text { on intention to } \\
\text { use the system }\end{array}$ & & & $\begin{array}{l}\text { - "Silo } \\
\text { mentality" }\end{array}$ \\
\hline 6. & $\begin{array}{l}\text { Facilitating con- } \\
\text { ditions have an } \\
\text { influence on } \\
\text { behavioural in- } \\
\text { tention to use the } \\
\text { system }\end{array}$ & & & $\begin{array}{l}\text { - "Stove- } \\
\text { piped report- } \\
\text { ing" }\end{array}$ \\
\hline 7. & $\begin{array}{l}\text { Self-efficacy } \\
\text { (ability to influ- } \\
\text { ence, affect, or } \\
\text { time required to } \\
\text { affect) has an } \\
\text { influence on } \\
\text { intention to use } \\
\text { the system }\end{array}$ & & & $\begin{array}{l}\text { - "Meeting } \\
\text { cancellations, } \\
\text { less though- } \\
\text { tful data } \\
\text { entry." } \\
\text { - "Available } \\
\text { time and } \\
\text { distance of } \\
\text { knowledge } \\
\text { holders." }\end{array}$ \\
\hline 8. & $\begin{array}{l}\text { Computer self- } \\
\text { efficacy will not } \\
\text { have a significant } \\
\text { influence on } \\
\text { intention. }\end{array}$ & & & $\begin{array}{l}\text { - "None. It } \\
\text { is there for } \\
\text { the taking. It } \\
\text { is just getting } \\
\text { the time." }\end{array}$ \\
\hline 9. & $\begin{array}{l}\text { Anxiety has an } \\
\text { influence } \\
\text { intention to use } \\
\text { the system }\end{array}$ & & $\begin{array}{l}\text { - "People don't } \\
\text { like change." } \\
\text { - "Negative beha- } \\
\text { viours" } \\
\text { - "None. My } \\
\text { manager is very } \\
\text { helpful when I go } \\
\text { to her to ask for } \\
\text { knowledge" }\end{array}$ & \\
\hline
\end{tabular}




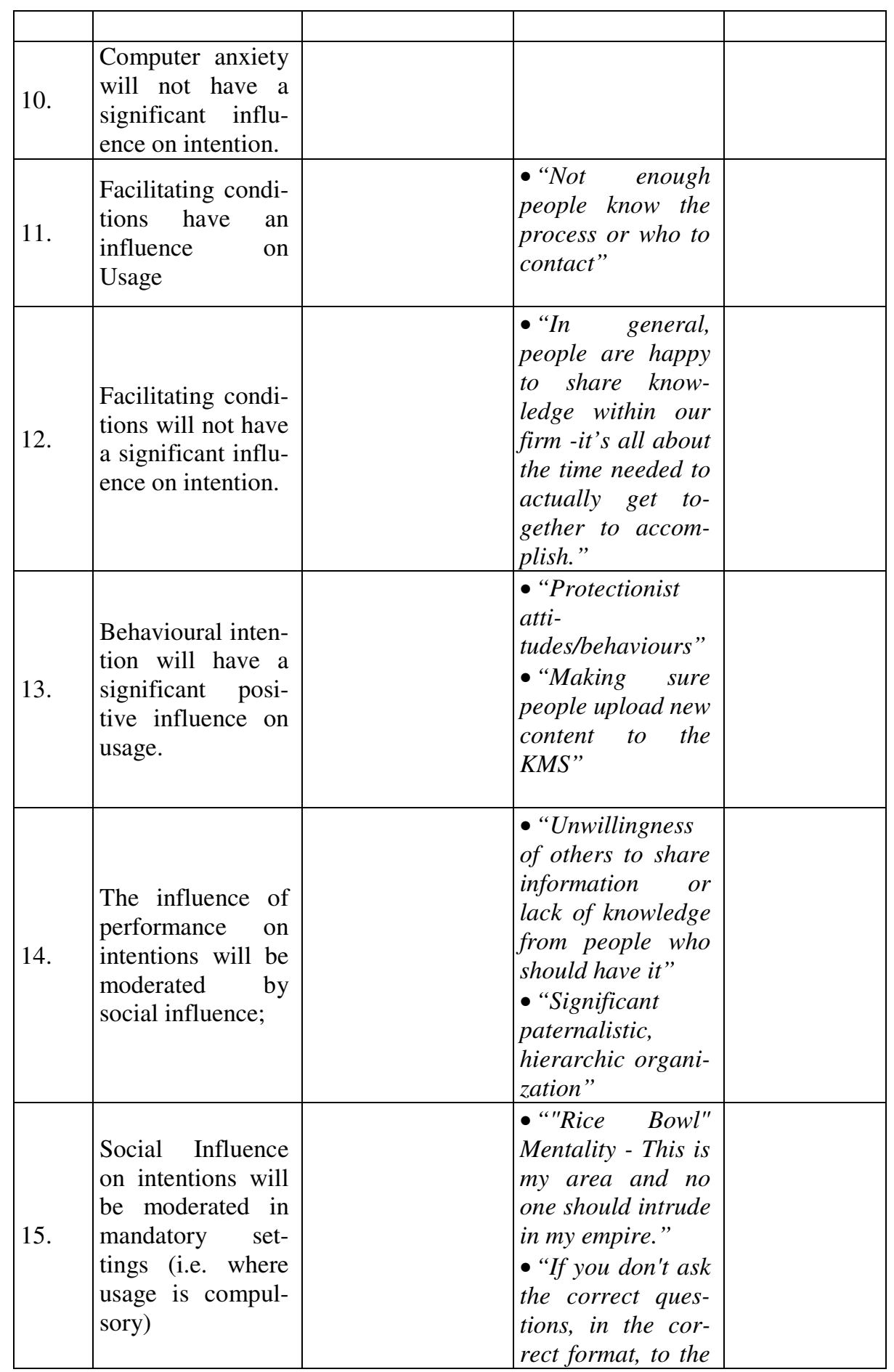




\begin{tabular}{|l|l|}
\hline $\mid \begin{array}{l}\text { correct person you } \\
\text { won't get the } \\
\text { answers you } \\
\text { need." } \\
\text { "Complete lack } \\
\text { of people offering } \\
\text { information, it has } \\
\text { to be pulled from } \\
\text { them." }\end{array}$ \\
\hline
\end{tabular}

In Table 4, we see that, in fact, all our propositions have been validated.

Our initial subset of propositions involved the use of technology, and our first proposition $(P l)$ related to system performance: if the system is not working well, then users cannot or will not use the system. Our second proposition $(P 2)$ related to how much effort was then needed to use the system and our respondents strongly believed that their KMS were too complicated and had very poor search facilities, thus meaning that they have to expend a great deal of effort to find what was needed, and thus they were not inclined to use the system. We then proposed that any current or prior attitudes towards technology (and knowledge) would influence whether or not people would use a KMS (P3). Clearly many of our participants believed strongly that knowledge was in people's heads and thus using technology would not help them find it (P4). They did agree however, that some explicit information could be found through the use of technology.

In relation to the organisational factors that affect people's intention to use a KMS, we first proposed that there would be a social influence on whether or not the system would be used (P5). Our respondents agreed that there was an inbuilt resistance to change in their organisations, including many negative behaviours that would prevent people from using a KMS. People were concerned only with their own section or department and were anxious to ensure that this knowledge stayed within their 'silo'. This could be negativity enhanced or alleviated by the facilitating conditions in these organisations $(P 6)$. But as many organisations still operate within a strict hierarchy or bureaucratic structure, then reporting will always go upwards for them thus knowledge sharing and knowledge acquisition will be limited to what is the minimum required for a report rather than an expansion of knowledge and encouragement to include others in the activity. Many of our respondents were critical of others and their use of the system which meant that they could not impact what knowledge was inputted $(P 7, P 8)$. Again behavioural conditions in organisations will dictate what is considered important and clearly knowledge sharing and the inputting of explicit or tacit knowledge into a KMS were not considered important for many. If they had the time, they would consider using it but this time was not available to them.

In relation to the human factors, we see that resistance to change was cited as a main reason why KMSs were not used in some organisations. Resistance is often caused by anxiety about personal performance in relation to technology and is cited by many authors as a key reason for difficulties in implementing any information system (IS), such as Akhavan, Jafari, Fathian (2005) discussed above. This would also apply to our proposition about anxiety $(P 9, P 10)$, where people would prefer to go to a manager rather than use a system even though they say that they have issues 
with such a system. People know who to ask when they want verbal knowledge, or at least who to ask in order to find out whom to ask... but with new systems they don't know the processes well enough or who they should ask when they have an issue, or need to find something that is not evident on the system. Facilitating conditions, such as organisational structure and training, and knowing people outside of their departmental silo come into effect, and, for many, these are not known or well understood $(P 11, P 12)$. Even where people are willing to share, if the conditions in which they have the time to share, and the managerial willingness for them to attend such things as communities of practice and share across these departmental silo walls, are not there, then knowledge sharing will not, and does not, take place.

If we then look again at people's behaviour, we can see that if they feel negatively towards a KMS, in that it is taking away their knowledge power, they will not upload their tacit knowledge into it, and will find reasons not to upload their explicit knowledge citing the lack of time more often than not $(P 13, P 14, P 15)$. If senior managers do not 'walk the talk' but continue to operate in a paternalistic and hierarchical manner then the social influence will be against usage of the KMS. However, mandatory use will ensure that some information is uploaded but not necessarily the right knowledge or all that you need to know. Some knowledge will be retained and may be very difficult to obtain as people protect their power and influence.

None of these above observations will be unexpected to those who read the theory about organisational behaviour and how it impacts on human behaviour in an organisation. But here we have proof of it happening in all cultures across the world. This is new information as we can compare our results across countries and organisational type. Over half our respondents from the United States for instance have issues in all three areas of KMS: technological, human, and organisational; across all sectors and sizes of organisations.

\section{Discussion, Conclusion and Directions for Future Research}

We studied the causes of success and failure and report the results from a survey which is not only the largest KM survey of knowledge workers, KM managers, and senior managers undertaken covering the whole world, but also represents all industrial sectors, and envelops all types of organisations. The size and scope of coverage of our study combined with qualitative and quantitative analyses of the data give a strong validity to our findings, and a wide applicability. We believe that all organizations can make some use of our recommendations in enhancing the success, and avoiding the failure, of their KMS. We summarize some of these results and their implications for the practice of managing knowledge in the paragraphs below.

Looking specifically at the subset of results taken from our open-ended questions answered by 108 participants from across many countries and cultures, we find that a number of conditions in three areas-Human Behaviour, Technical Issues, and Organizational Issues - need to be met before a KMS can be successful. There are 15 conditions that we have tested through content analysing the results of the free-form input from the 108 participants as formulated in fifteen propositions. Based on our analyses, we find that all our propositions are validated. We can therefore suggest that unless the conditions suggested by these 15 propositions are in place in any organisation, a KMS will not be fully successful. 
We therefore recommend that, firstly, the 19 questions we have designed to ensure adherence to Clegg's 19 Sociotechnical Principles (2000) are used to help design the technical system; and secondly, that the 15 technology, human and organisational conditions validated by our research are put in place before and during the implementation of KMS. This implies that the organisational structure and silos will need to be flattened, and communication established between all departments at all levels. This will require a reduction in hierarchy in organizations where the KMS function is important. It also requires encouraging and rewarding the sharing of information through organizational policies, since we find that people do not share information because they do not want to part with their knowledge, or they do not feel that it is one of their tasks or job role. Our survey reveals that there is much negative behaviour in organizations that gives employees a sense of insecurity and which causes an inbuilt resistance to change. Since people who feel secure do not resist change, organizations should develop a culture, policy and structure that make employees feel secure. This will set behavioural conditions that emphasize the importance of not resisting change and encourage the sharing of knowledge. A system that promotes and rewards knowledge sharing behaviour rather than the one that results in the hoarding of knowledge, will need to be put in place. Training about the importance of knowledge sharing and the use of the new system will need to begin at the design stage when stakeholders will need to be involved to ensure that searching in particular, is easy and relevant. A simple system with simple interfaces that are easy to use will be required and participation of the major stakeholders in design and development prototyping will help ensure that the system better meets their needs.

Finally, time will need to be built into daily and weekly tasks for knowledge sharing including regular meetings of communities of practice when best practice can be shared and innovatory knowledge can be developed. The start of knowledge sharing will have to begin with management. And, that will also be the start of building factors for the success of a KMS, and for avoiding factors that will cause a KMS to fail.

Our analysis of the underlying factors relating to KMS success and failure provides a number of limitations that suggest that further research on this theory would be valuable. Firstly, while our survey sample of 1034 participants is very extensive and fully represents all economic sectors, industries, and regions of the world, the sample of open-ended question participants is biased in favour of the UK and USA. Future research may be directed by expanding the sample to include non-Western cultures and other regions of the world. Although intuitively we do not believe that that would make any new revelations contradicting ours, it would hopefully reaffirm what we found or may help update it.

Secondly, a few in-depth case studies from several economic sectors, global regions, and industries, and several organisations would validate the design principles and underlying failure factors given in this paper. One could propose that some variations coming from such diverse case studies may help expand or, more specifically, sharpen the application of these principles and factors to specific cases.

Thirdly, whilst the survey was completed by 1034 participants, the KMS success and failure theory was tested at a very general level. The future research can better tie all aspects of this general theory by revalidating them more specifically; therefore, a comprehensive survey testing specifically these 15 propositions would help apply the new theory at a more practical level. 


\section{References}

Akhavan, P., Jafari, M., Fathian, M.: Exploring Failure-Factors Of Implementing Knowledge Management Systems In Organisations. Journal Of Knowledge Management Practice 6 (2005), http: / /www. tlainc.com/articl85.htm (accessed October 19, 2012)

Berelson, B.: Content analysis in communication research. The Free Press, Glencoe (1952)

Cherns, A.: The principles of sociotechnical design. Human Relations 29(8), 783-792 (1976)

Cherns, A.: The principles of sociotechnical design revisited. Human Relations 40(3), 153-162 (1987)

Clegg, S.: Sociotechnical Principles for System Design. Applied Ergonomics 31(5), 463-477 (2000)

Coakes, J., Coakes, E.: Sociotechnical Concepts applied to Information Systems. In: Cooper, C.L., Argyris, C., Starbuck, W. (eds.) Management Information Systems. Encyclopaedia of Management (7), pp. 1024-1029. Jaico Publishing House (2005)

Coiera, E.: Putting the technical back into socio-technical systems research. International Journal of Medical Informatics. 76(1), S98-S103 (2007)

Davenport, T.H., DeLone, D.W., Beers, M.C.: Successful knowledge management projects. Sloan Management Review 39(2), 43-57 (1998)

DeLone, W.H., McLean, E.R.: Information systems success: The quest for dependent variable. Information Systems Research 3(1), 60-95 (1992)

DeLone, W.H., McLean, E.R.: Information systems research revisited. In: Proceedings of 35th Hawaii International Conference on System Sciences. IEEE Computer Society (January 2002)

Dixon, N.M.: The Organizational Learning Cycle: How we can learn collectively. Gower Publishing, New York (1999)

Hurley, L.: Reasons why knowledge management systems fail, Helium (April 27, 2010), http: / / www. helium.com/items/1816248-why-do-knowledgemanagement-information-systems-fail (accessed November 22, 2012)

Jennex, M., Olfman, L.: A knowledge management success model: An extension of DeLone and McLean's IS success model. In: AMCIS 2003 Proceedings. Paper 330 (2003), http://aisel.aisnet.org/amcis2003/330

Klein, H.K., Myers, M.D.: A Set of Principles for Conducting and Evaluating Interpretive Field Studies in Information Systems. MIS Quarterly 23(1), 67-93 (1999)

Kulkarni, U.R., Ravindran, S., Freeze, R.: A knowledge management system success model: Theoretical development and empirical validation. Journal of Management Information System 23(3), 309-347 (2006)

Massey, A.P., Montoya-Weiss, O'Driscoll, T.M.: Knowledge management in pursuit of performance: Insights from Nortel Networks. MIS Quarterly 26(3), 269-289 (2002)

Peute, L., Aartsb, J., Bakkerc, P.J.M., Jaspers, M.W.M.: Anatomy of a failure: A sociotechnical evaluation of a laboratory physician order entry system implementation. International Journal of Medical Informatics 79(4), e58-e70 (2010)

Stemler, S.: An overview of content analysis. Practical Assessment, Research \& Evaluation 7(17) (2001)

Tsinakis, M., Kouroubali, A.: Organizational factors affecting successful adoption of innovative eHealth services: a case study employing the FITT framework. International Journal Medicine Information 78(1), 39-52 (2009)

Whitworth, V., Bañuls, C., Cheickna, S., Mahinda, E.: Expanding the criteria for evaluating socio-technical software. IEEE Transactions On Systems, Man, And Cybernetics-Part A: Systems And Humans 38(4), 777-790 (2008)

Wu, J.-H., Wang, Y.-M.: Measuring KMS success: A respecification of the DeLone and McLean's model. Information \& Management 43(6), 728-739 (2006) 